\title{
Synthesis, Characterization and Magnetic Properties of a Novel Disulfonate-pillared Copper Hydroxide $\mathrm{Cu}_{2}(\mathrm{OH})_{3}(\mathrm{DS} 4)_{1 / 2}, \mathrm{DS} 4=1,4-\mathrm{Butanedisulfonate}$
}

\author{
Seong-Hun Park" and Cheol Eui Lee \\ Energy Nano Material Team, Korea Basic Science Instifute (KBSI), Daejeon 305-333, Korea. "E-mail: shunpark@kbsi.re.kr \\ "Institute for Nano Science and Department of Physics, Korea University, Seoul 136-701, Korea \\ Received Mav 11, 2006
}

\begin{abstract}
We report the preparation, structure and magnetic properties of a new pillared complex, copper(II) hydroxy1,4-butanedisulfonate, $\mathrm{Cu}_{2}(\mathrm{OII})_{3}\left(\mathrm{O}_{3} \mathrm{SC}_{4} \mathrm{II}_{4} \mathrm{SO}_{3}\right)_{1 / 2}$. The titled compound was obtained by anion exchange, using copper hydroxyl nitrate $\left(\mathrm{Cu}_{2}(\mathrm{OII})_{3} \mathrm{NO}_{3}\right)$ as the starting material. $\Lambda$ ccording to the XRD data, this compound exhibits a pillared layered structure with organic layers tilted between the copper hydroxide layers with a tilt angle of $21.8^{\circ}$. FTIR spectroscopy confirms total exchange of nitrate by the sulfonate and indicates that the sulfonate functions are linked to the copper(II) ions with each aliphatic chain bridging the adjacent hydroxide layers. $\Lambda$ ccording to the dc and ac magnetic measurements, the title compound is a metamagnet consisting of spin-canted antiferromagnetic layers, with a Neel temperature of $11.8 \mathrm{~K}$.
\end{abstract}

Key Words : Anion exchange reaction, Disulfonate, Triangular 2D magnetic system, Magnetism, Inorganic/ organic hybrid layered structure

\section{Introduction}

Transition metal hydroxides have attracted a great deal of interest in both science and technology on account of their wide variety of applications such as ion exchangers, catalysis, and hosts in intercalation compounds, ${ }^{1-3}$ They can be used to produce many types of low-dimensional magnetic materials. ${ }^{4}$ These materials also find use as precursors for the fabrication of one-dimensional nanostructures. " These properties are mainly related to their structural features. Layered metal hydroxide derivatives are derived from layered metal hydroxide $\mathrm{M}(\mathrm{OH})_{2}$ in two ways: layered double hydroxides (LDHs: $\mathrm{M}_{1_{\mathrm{x}}} \mathrm{M}_{\mathrm{x}}(\mathrm{OH})_{2} \times \mathrm{xA} \cdot \mathrm{zH}_{2} \mathrm{O}$ ) and hydroxy double salts ( $\left.\mathrm{HDSs}: \mathrm{M}(\mathrm{OH})_{2-x}\left(\mathrm{~A}^{\mathrm{n}}\right)_{\mathrm{x} / \mathrm{n}} \cdot \mathrm{zH}_{2} \mathrm{O}\right)$. LDHs are derived from a layered hydroxide, $\mathrm{M}(\mathrm{OH})_{2}$, by replacing some of the $\mathrm{M}^{2+}$ ions in the octahedral sites with a trivalent ion, $\mathrm{M}^{3+}$. The positive charge of the layers is counterbalanced by the intercalating anions together with water molecules between the layers. In this case, interlayer cohesion is provided by hydrogen bonding between the hydroxy groups of the inorganic sheets and the intercalated anions as well as by electrostatic interactions.

HDSs are also derived from brucite-like $\mathrm{M}(\mathrm{OH})_{2}$ by substituting hydroxyl groups with intercalating anions $\left(\mathrm{A}^{\mathrm{n}-}\right)$, located in the space between the layers. Outstanding examples are the layered transition metal hydroxides $\mathrm{M}_{2}(\mathrm{OH})_{3} \mathrm{X} \cdot \mathrm{zH}_{2} \mathrm{O} \quad(\mathrm{M}=\mathrm{Co}, \mathrm{Ni}$ and $\mathrm{Cu} ; \mathrm{X}=$ inorganic or organic anion). These systems contain positively charged magnetic sheets, which are formed by planar triangular networks of metal ions that are interleaved by an anion, $\mathrm{X}^{-6}$. A remarkable feature of these systems is that the intercalation of large organic species enables the interlayer spacing to be modulated over very large distances, allowing the magnetic properties to be tuned by controlling the interlayer separation. ${ }^{7}$ These systems appear to be suitable for the design of inorganic-organic hybrid materials with outstanding magnetic properties because the inorganic layers provide the pathway for cooperative magnetism, and the organic molecules act as a structural template controlling the interlayer spacing.

Many studies have examined the role of intercalated anions (charge, length, chain stacking, binding mode, presence of $\pi$-electrons, etc.) on the magnetic properties of these materials focused mainly on carboxylates and sulfates $^{8-12}$ In particular, the magnetic properties of materials involving copper(II) ions are quite sensitive to any structural modification. For example, the n-alkyl carboxylate derivatives with a bilayer structure show an anomalous behavior ranging from antiferromagnetic to ferromagnetic states with varying layer spacing. In contrast, the analogous $n$-alkylsulfate derivatives with monolayer structures were all antiferromagnets. Therefore, there may be large variations in the magnetic behavior depending on the chain length and the type of anion exchanged.

Sulfonate anions $\left(\mathrm{RSO}_{3}^{-}\right.$) have received less attention due to the preconception that they are weakly coordinating ligands. Therefore, there are few reports of alkylsulfonate intercalated compounds in the literature. ${ }^{13}$ We recently reported a detailed study ${ }^{14}$ on the synthesis and characterization of the spectroscopic and magnetic properties of a series of the layered copper hydroxy anhydrate salts, $\mathrm{Cu}_{2}(\mathrm{OH})_{3}\left(\mathrm{C}_{n} \mathrm{H}_{2 n+1} \mathrm{SO}_{3}\right)$ with $n=6,8$, and 10. All the compounds with an interdigitated bilayer structure showed a similar metamagnetic behavior with a Neel temperature of approximately $11 \mathrm{~K}$. In particular, it was found that their magnetic properties were affected by the presence of hydrogen bonding between the sulfonate headgroup and the hydroxide anion of the inorganic layer: ${ }^{1+(b)}$

As a continuation of our investigations of layered systems, the present work is concerned with the synthesis and 
characterization of a new disulfonate-pillared copper(II) hydroxide, $\mathrm{Cu}_{2}(\mathrm{OH})_{3}\left(\mathrm{SO}_{3} \mathrm{C}_{4} \mathrm{H}_{8} \mathrm{SO}_{3}\right)_{1 / 2}[\mathrm{Cu}-D S 4]$, also examining its magnetic properties. To our knowledge, there is no layered copper(II) hydroxide-based magnet with a sulfonate-pillared structure. The particular aim of this study was to examine the effect of the intercalated anion on the magnetic behavior of the new disulfonate-pillared copper hydroxide salt.

\section{Experimental Section}

Synthesis. The $C u-D S 4$ was prepared by anion exchange method, starting from copper (II) hydroxy nitrate, $\mathrm{Cu}_{2}(\mathrm{OH})_{3}$ $\mathrm{NO}_{3}$. The parent material, $\mathrm{Cu}_{2}(\mathrm{OH})_{3} \mathrm{NO}_{3}$, was prepared as follows: a reaction of $\mathrm{CuO}(15.9 \mathrm{~g}, 0.2 \mathrm{~mol})$ with $\mathrm{Cu}\left(\mathrm{NO}_{3}\right)_{2}$. $3 \mathrm{H}_{2} \mathrm{O}(60.4 \mathrm{~g}, 0.025 \mathrm{~mol})$ in $250 \mathrm{~mL}$ water yielded a bluishgreen precipitate. The title compound was obtained by anion exchange: $200 \mathrm{mg}$ of the parent material and $0.1 \mathrm{~mol}$ of $1,4-$ butanedisulfonate sodium salt were dispersed in $20 \mathrm{~mL}$ of distilled water. The mixture was stirred in an air-free round flask for $48 \mathrm{~h}$ at room temperature. The shiny blue powder was filtered, washed with distilled water and acetone, and dried under vacuum at $30^{\circ} \mathrm{C}$.

Characterization. Elemental analysis for $\mathrm{C}, \mathrm{H}, \mathrm{N}, \mathrm{S}$, and $O$ was performed at the Seoul Center of the Korea Basic Science Institute (KBSI). Thermogravimetric analysis (TGA) was performed using a Perkin TGA themobalance up to $1000^{\circ} \mathrm{C}$ under nitrogen gas. The powder X-ray diffraction (PXRD) data was collected on a MAC Science diffractometer (MXP3A-HF) operating at $40 \mathrm{kV}$ and $30 \mathrm{~mA}$ in the Bragg-Brentano $\theta-2 \theta$ mode (CuK $\alpha, \lambda=1.5418 \AA$ ). The FTIR spectra were obtained using a FTIR Bomem Michelson spectrometer. The $\mathrm{Cu}-D S 4$ sample was cast on a $\mathrm{KBr}$ pellet and measured in the transmission mode from 500 to 4000 $\mathrm{cm}^{-1}$ with a resolution of $4 \mathrm{~cm}^{-1}$.

The magnetic measurements of the powdered samples enclosed in a medical cap were carried out using a Quantum Design MPMS-7 SQUID magnetometer. The temperature dependence of the static susceptibility was examined at temperatures ranging from $5-300 \mathrm{~K}$ in a magnetic field of 5 kOe. The molar magnetic susceptibility $\chi_{\mathrm{M}}$ was calculated by using Pascal's additive scheme. The hysteresis curves were obtained at $5 \mathrm{~K}$ in applied fields of up to $50 \mathrm{kOe}$, after cooling with no applied field throughout the magnetic transitions. The ac susceptibility measurements were performed over the1-Oe field in the frequency range of 10 $10000 \mathrm{~Hz}$ at temperatures ranging from $5-60 \mathrm{~K}$ (PPMS, Quantum Design Co.).

\section{Results and Discussion}

Synthesis and characterization. The Cu-DS4 was obtained as a light-blue powder by anionic exchange at room temperature, starting from copper(II) hydroxy nitrate, $\mathrm{Cu}_{3}(\mathrm{OH})_{3} \mathrm{NO}_{3}$. Elemental analysis confirms the composition of Cu-DS4: $\mathrm{C}_{2} \mathrm{Cu}_{2} \mathrm{H}_{7} \mathrm{O}_{6} \mathrm{~S}$, obs (calc) N: $0.00(0.00)$; $\mathrm{C}: 8.34$ (8.39); H: $2.26(2.46)$; $\mathrm{S}: 11.18$ (11.18), which indicated the

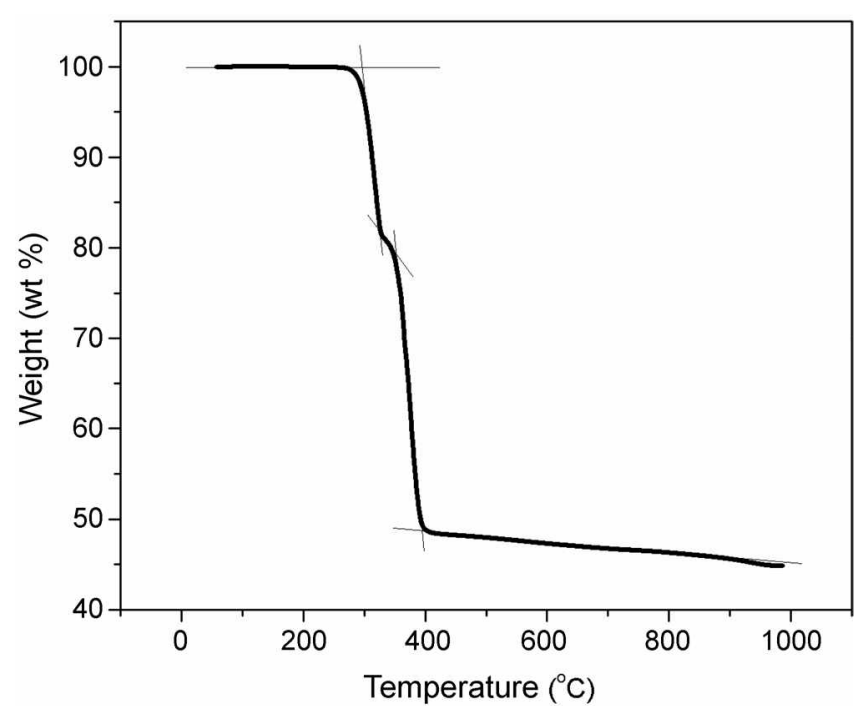

Figure 1. TGA curve of Cu-DS4, exhibiting a high thermal stability up to $270^{\circ} \mathrm{C}$.

total exchange of nitrate anions and confirmed the composition of the Cu-DS4 material. Thermogravimetric analysis (TGA) was performed using a Perkin TGA thermobalance up to $1000^{\circ} \mathrm{C}$ under nitrogen gas and is shown in Figure I, which reveals that the Cu-DS4 has no lattice water and exhibits a high thermal stability up to $270^{\circ} \mathrm{C}$.

Figure 2 shows the XRD patterns of the Cu-DS4 and the starting material. Both compounds exhibit a lamellar structure, as is evident from powder XRD patterns by intense $(00 /)$ reflections, up to at least the third order. It is first essential to confirm the completeness of the anion exchange reaction in the Cu-DS4 compound, which can be determined simply from the relative changes in the peak positions with respect to the starting material. In this case, it can be concluded that the total exchange reaction was successful because there were no reflections observed from the starting compound.

In addition, thanks to high crystallinity, the Cu-DS4 can be indexed on the basis of a monoclinic structure, so that the resultant cell parameters can be compared with those of the parent material. The cell parameters, $a=5.79319(79) \AA$, $b=5.94419(66) \AA, c=10.9092(18) \AA, b=96.6288(95)^{\circ}$, and $V=373.158(90) \AA^{3}$, are refined with sufficient precision using the "TREOR 90 " indexing software and by profile (Pawley) refinement in the Materials Studio v2.2 platform. The lattice parameters of the $a b$ plane of the title compound are quite similar to those of the parent material with the Botallackite structure $(a=5.598 \AA, b=6.085 \AA, c=6.930$ $\left.\AA, b=94.75^{\circ}\right)$, only the basal spacing $(d=10.836 \AA)$ changing in accordance with the size of the disulfonate anion. The thickness of the inorganic layer was estimated to be $3.0 \AA$. The gallery distance $(=10.836-3.0=7.836 \AA)$ between the layers in the $\mathrm{Cu}-\mathrm{DS} 4$ was shorter than those in the 1,4butanedisulfonate $(8.44 \AA){ }^{15}$ Therefore, the organic layer is tilted between the inorganic layers with a tilt angle $21.8^{\circ}$.

From the XRD data analysis, we were able to extract the 


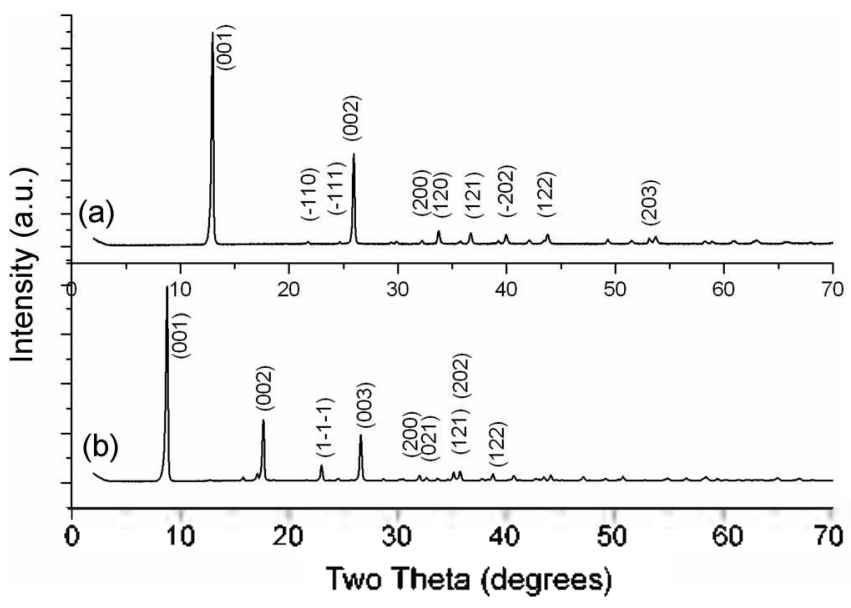

Figure 2. Powder X-ray diffraction patterns of (a) $\mathrm{Cu}_{2}(\mathrm{OH})_{3} \mathrm{NO}_{3}$ (parent) and (b) Cu-DS4, showing a lanellar structure.

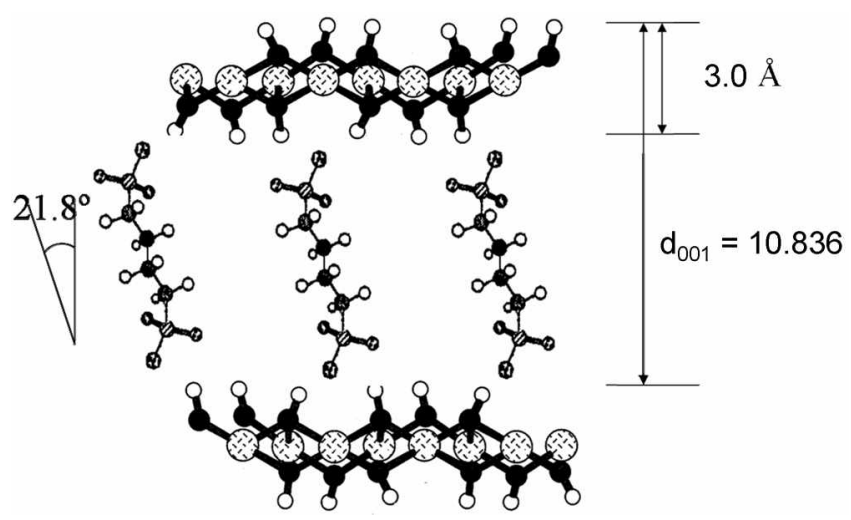

Figure 3. Schematic Structural Model of the Cu-DS4, showing the layered structure with organic layers tilted between the inorganic layers with a tilt angle of $21.8^{\circ}$.

schematic structural model for the Cu-DS4 as is displayed in Figure 3 , which consists of alternating inorganic copper hydroxide layers and organic disulfonate layers of aligned alkyl chains forming a pillared structure.

FTIR spectroscopy is an effective technique for checking the completeness of the anion exchange reaction as well as for understanding the molecular structure of the organic anions in the interlayer spaces. ${ }^{16}$ The whole patterns of characteristic IR spectra for Cu-DS4 are shown in Figure 4. For comparison, the IR spectra of the parent material, $\mathrm{Cu}_{2}(\mathrm{OH})_{3} \mathrm{NO}_{3}$, and 1,4-butanedisulfonate sodium salt are also shown. The most distinct features for the Cu-DS4 occur at $2900-3500 \mathrm{~cm}^{-1}$ and $1000-1500 \mathrm{~cm}^{-1}$, which correspond to the hydroxyl stretching vibration and the stretching vibration of the anions, respectively.

It is well known that there are two types of nonlinear hydrogen bonds ${ }^{17}$ in the structure of $\mathrm{Cu}_{2}(\mathrm{OH})_{3} \mathrm{NO}_{3}$ : The first has a bond length $\mathrm{R}(\mathrm{O}-\mathrm{H} \cdots \mathrm{O})$ of $2.859 \AA$. The second is bifurcated with individual bond lengths of 2.947 and 3.037 $\AA$. Therefore, the sharp absorption band at $3600-3540 \mathrm{~cm}^{-1}$ and the broad asymmetric absorption band at 3500-3400 $\mathrm{cm}^{-1}$ can be assigned to the stretching vibration, $v_{\mathrm{OH}}^{\prime}$, of the

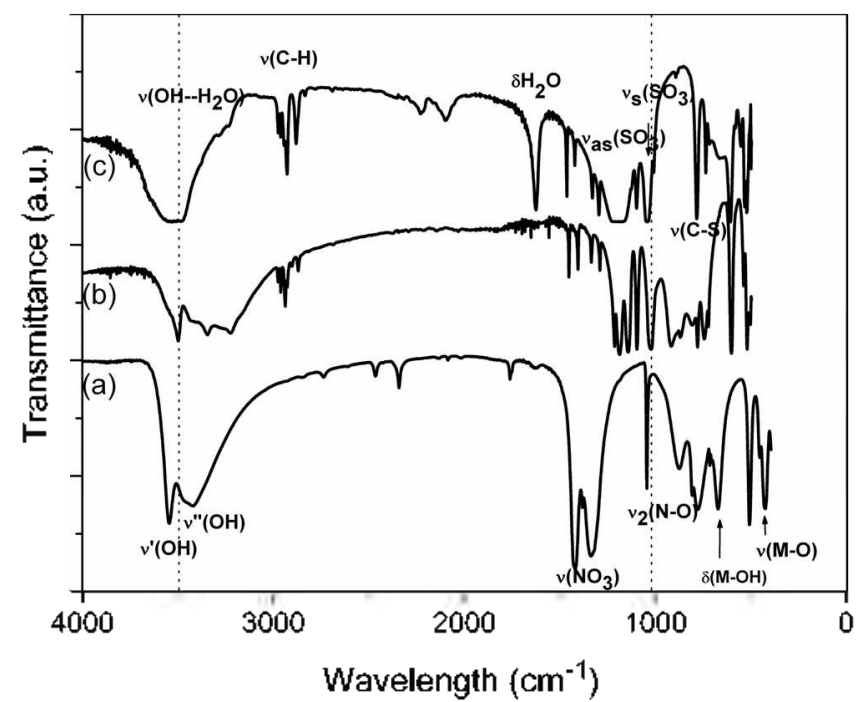

Figure 4. FTIR spectra of (a) $\mathrm{Cu}_{2}(\mathrm{OH})_{3} \mathrm{NO}_{3}$ (parent), (b) Cu-DS4, showing the completc anion exchange reaction, and (c) 1,4butanedisulfonate sodium salt.

almost free $\mathrm{OH}^{-}$group and to the stretching mode, $v^{\prime \prime}$ or, of the stronger hydrogen bond $[\mathrm{R}(\mathrm{O}-\mathrm{H} \cdots \mathrm{O})=2.86-2.95 \AA]$, respectively. On this line, the positions of the $\mathrm{OH}$ stretching and bending vibrations of $\mathrm{Cu}_{2}(\mathrm{OH})_{3} \mathrm{NO}_{3}$, as shown in Figure 4(a), are in good agreement with earlier reports. ${ }^{18}$ For the disulfonate-pillared case (Figure $4(\mathrm{~b})$ ), $v_{\text {orr }}^{\prime}$ of the hydroxy groups is shifted to a lower frequency $\left(3545 \rightarrow 3499 \mathrm{~cm}^{-1}\right)$ and the $v^{\prime \prime}$ or of the hydroxy groups is further separated, which might be due to the weakness of the $\mathrm{O}-\mathrm{H}$ bond. In addition, the weakness and/or absence of a broad feature in the hydrogen bonding region $\left(3550-3200 \mathrm{~cm}^{-1}\right)$ and the $\mathrm{H}-$ $\mathrm{O}-\mathrm{H}$ bending mode $\left(1630-1600 \mathrm{~cm}^{-1}\right)$ are indicative of no lattice water, which is in accordance with the elemental analysis.

On the other hand, the most distinct features are noticed in the frequency region of $1000-1500 \mathrm{~cm}^{-1}$ : the disappearance of the vibrations due to the $\mathrm{N}-\mathrm{O}$ from the nitrate group at approximately $1423 \mathrm{~cm}^{-1}$, and the appearance of the $\mathrm{S}-\mathrm{O}$ band from the sulfonate group, which confirms the total exchange of nitrate ions by the sulfonate anions. In detail, Cu-DS4 exhibits the characteristics of the fundamental and the split $v_{3}(\mathrm{~S}-\mathrm{O})$ stretching modes in the range 1000-1250 $\mathrm{cm}^{-1}$. Two strong bands observed in this region can be assigned to the symmetric $v_{\mathrm{s}}\left(\mathrm{SO}_{3}{ }^{-}\right)$and anti-symmetric $v_{\mathrm{as}}\left(\mathrm{SO}_{3}{ }^{-}\right)$stretching vibrations of the sulfonate group. The Cu-DS4 exhibits triplet split anti-symmetric $v_{\mathrm{as}}\left(\mathrm{SO}_{3}{ }^{-}\right)$ stretching bands at 1216,1189 , and $1146 \mathrm{~cm}^{-1}$ and a single narrow symmetric $v_{\mathrm{s}}\left(\mathrm{SO}_{3}^{-}\right)$stretching band at $1026 \mathrm{~cm}^{-1}$, respectively, whereas the two bands appear at 1202 and 1046 $\mathrm{cm}^{-1}$ in the free ligand. The low-wavenumber shift of the $\mathrm{SO}_{3}$ symmetry stretching vibration shows the formation of hydrogen bonds between the $\mathrm{SO}_{3}{ }^{-}$ion and $\left[\mathrm{Cu}_{2}(\mathrm{OH})_{3}\right]^{+}$ layer. The coordination chemistry of the sulfonate group from the IR studies has, until quite recently, remained relatively unstudied. However, IR spectra for Cu-DS4 in sulfonate group regions are different from those for the 
corresponding anion sodium salt suggesting the sulfonate group are directly bonded to a copper(II) ion with complex bonding modes, which is believed to be a bis-monodentate, as well as hydrogen bonding interaction instead of an ionic interaction.

Magnetic properties. The magnetic properties of materials involving copper(II) ions are quite sensitive to any structural modifications that may be introduced by sulfate, sulfonate or carboxylate bridging species. A remarkable feature of those systems is that there is a strong correlation between the magnetic properties and the stoichiometry, as determined by the lattice water content. In particular, for the sulfonate derivatives, anhydrous compounds possess antiferromagnetic long-range order ${ }^{14}$ but hydrated phases exhibited no sign of long-range order. ${ }^{13(a)}$ In the case of alkylsulfonate anhydrous derivatives, hydrogen bonding was observed between the sulfonate headgroup, and the hydroxide anion of inorganic layer is reflected on their magnetic properties. ${ }^{14 k\rangle}$ Therefore, magnetic measurements were carried out on the newly synthesized Cu-DS4 compound with no lattice water in order to observe the effect of the intercalated anion on the magnetic behavior of the inorganic layer with a disulfonate bridging ligand.

The temperature-dependent magnetic susceptibility $\chi_{\mathrm{M}}$ and $\chi_{\mathrm{M}} T$, as measured over the temperature range of $5-300 \mathrm{~K}$ in an applied field of $5 \mathrm{kOe}$, are presented in Figure 5. The magnetic susceptibility, $\chi_{\mathrm{M}}$, increased with decreasing temperature, reaching a broad maximum of $0.0316 \mathrm{~cm}^{3} \mathrm{~mol}^{-1}$ at $c a .13 \mathrm{~K}$. The magnetic susceptibility then decreased sharply to $0.0248 \mathrm{~cm}^{3} \mathrm{~mol}^{-1}$ at $5 \mathrm{~K}$. This broad maximum is indicative of low-dimensional magnetism. ${ }^{19}$ At high temperatures, the $\chi_{\mathrm{M}} T$ value of $0.8693 \mathrm{~cm}^{3} \mathrm{~mol}^{-1} \mathrm{~K}$ corresponds to two $\mathrm{Cu}$ (II) $\left(\mathrm{d}^{9}, \mathrm{~S}=1 / 2\right)$ per mole (ca. $\left.0.8 \mathrm{~cm}^{3} \mathrm{~mol}^{-1} \mathrm{~K}\right) . \chi_{\mathrm{M}} T$ decreased smoothly with decreasing temperature, finally approaching zero, which suggests an antiferromagnetic (AFM) interaction. The magnetic data above $100 \mathrm{~K}$ can be fitted to the Curie-Weiss law with $C=0.8983 \mathrm{~cm}^{3} \mathrm{~mol}^{-1} \mathrm{~K}$ and $\Theta=-10.33 \mathrm{~K}$, which indicates an antiferromagnetic (AFM) interaction. The magnetic susceptibility was fitted in the paramagnetic regime to determine the in-plane exchange interaction between the copper (II) jons. Using the hightemperature series expansions for the spin 1/2 2D Heisenberg triangular lattice, ${ }^{20}$ very good agreement between theory and the experimental findings was obtained with $J / k=-5.76 \mathrm{~K}$. However, anomalous magnetic behaviors were observed below $11.8 \mathrm{~K}$. The magnetic susceptibilities were bifurcated with the magnetic history. The inset in Figure 5 shows the zero-field-cooling ( $\mathrm{ZFC}$ ) and field-cooling ( $\mathrm{FC}$ ) dc susceptibilities. A bifurcation point was observed at $11.8 \mathrm{~K}$, which is characteristic of a spontaneous moment due to spin canting.

Further information on the three-dimensional ordering was provided by the temperature dependence of the ac magnetic susceptibility measurements (Figure 6). The inphase $\chi^{\prime}$ of the ac susceptibility increased with decreasing temperature, forming a rather broad maximum at approximately $13 \mathrm{~K}$ with an additional sharp peak appearing at 11.8 $\mathrm{K}$, while the out-of-phase susceptibility showed a sharp peak

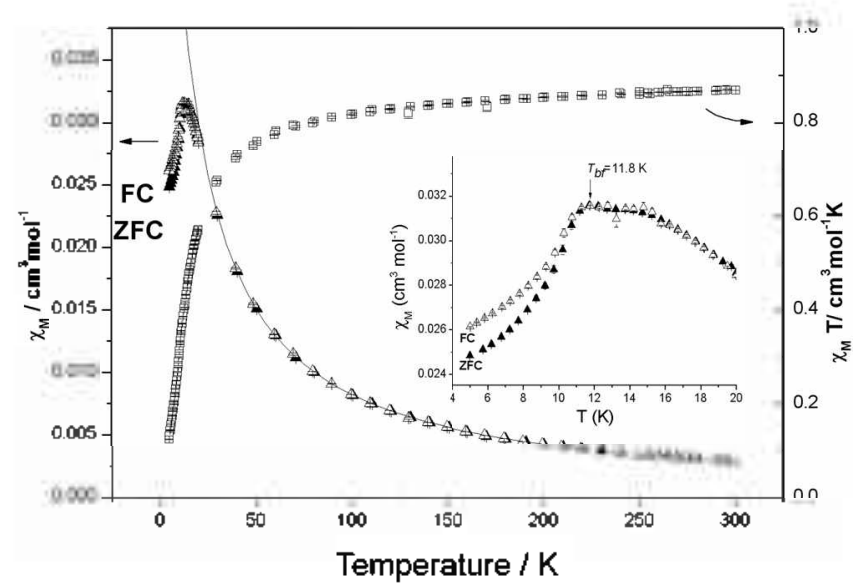

Figure 5. The temperature dependence of $\chi_{M}$ and $\chi_{M} T$ for Cu-DS4 in a magnetic field of $5 \mathrm{kOc}$. The solid line indicates a high temperature fit to the 2D Heisenberg triangular lattice model. Inset: a zoom of the low-temperature region in the dc magnetic susceptibility, exhibiting a ZFC and $\mathrm{FC}$ data merging at $11.8 \mathrm{~K}$.

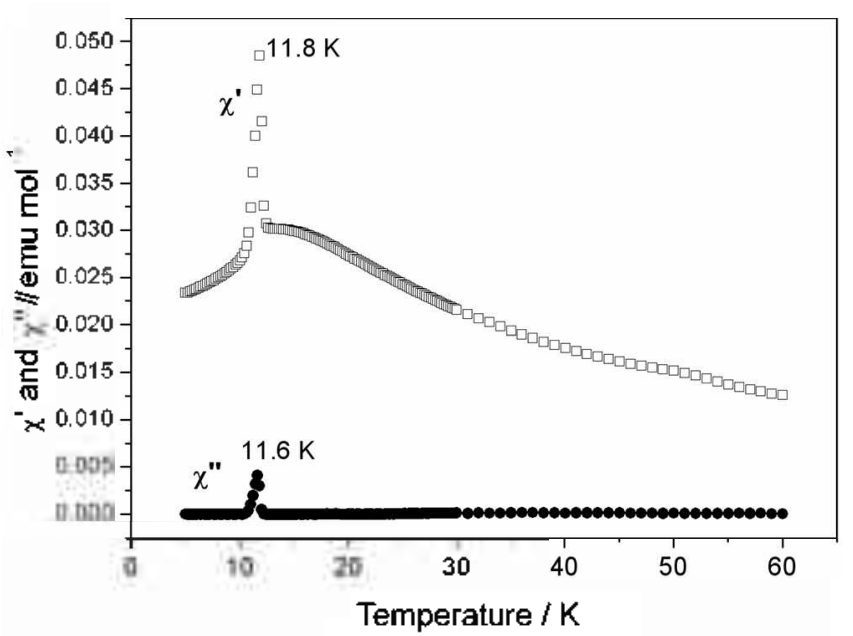

Figure 6. The temperature dependence of the ac magnetic susceptibilitics incasured in a I Oe field oscillating at $10 \mathrm{kHz}$.

at $11.6 \mathrm{~K}$, indicating a ferromagnetic (FM) order with $T_{c}=$ $11.8 \mathrm{~K}$. No frequency-dependent behavior was observed.

Figure 7 shows the sigmoidal shape of the magnetization versus field plot below $T_{K}$ (at $5 \mathrm{~K}$ ). The magnetization first increases slowly with magnetic field, as is nomally observed for a typical antiferromagnet. It then increases further above the critical field, indicating a field-induced transition from an antiferromagnetic state to a weak ferromagnetic state. The critical field at $5 \mathrm{~K}$ was $c a .25 \mathrm{kOe}$, which is estimated to be the field at which a maximum $\partial M / \partial H$ value is reached. A more careful inspection of the low-field regime in the $M-H$ plot (inset of Figure 7 ) revealed a weak hysteresis behavior with a coercive field of $100 \mathrm{Oe}$, remanent magnetization of $2.45 \mathrm{emu}^{\circ} \mathrm{Oe} \cdot \mathrm{mol}^{-1}$, and a change in slope at 400 $O$ e in $\partial M / \partial H-H$ plot. These features indicate a metamagnet consisting of spin-canted antiferromagnetic layers. The observed behavior is similar to those for transition metal hydroxides $\mathrm{M}(\mathrm{OH})_{2}$, of which $\mathrm{M}=\mathrm{Fe}$, $\mathrm{Co}$, and $\mathrm{Ni}$, are well- 


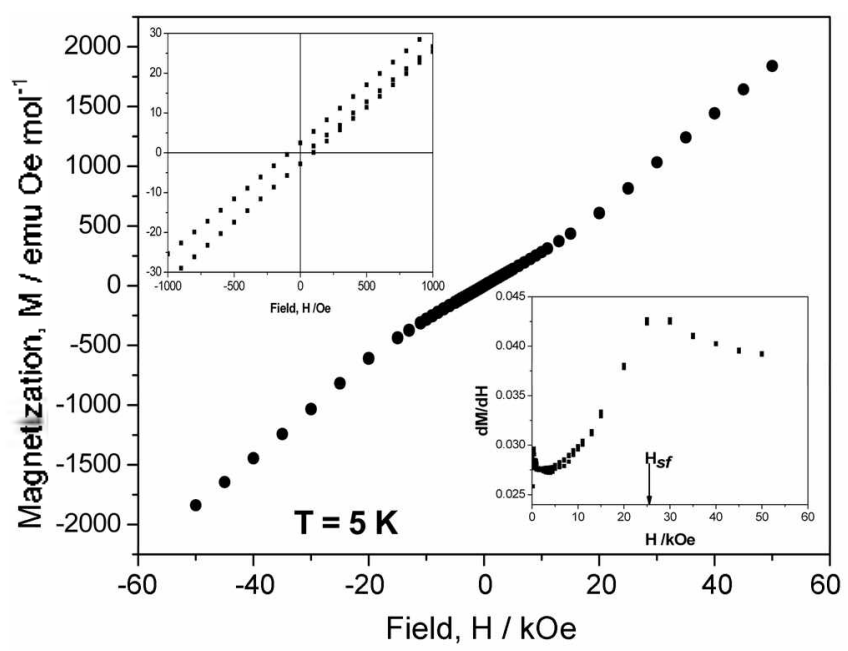

Figure 7. The field dependence of magnetization for Cu-DS4 at 5 K. Inset: (top) low-field region, show a small hysteresis, (bottom) the derivative of the field dependence, clearly showing a change in slope in two different region: at $400 \mathrm{Oc}$ and $25 \mathrm{kOc}$.

\section{characterized metamagnets. ${ }^{21}$}

The magnetic properties of materials involving copper(II) jons are dependent on the nature of the intercalated species, the character of the in-plane and inter-plane interactions, and the interlayer separations. Drillon and Panissod ${ }^{22}$ have proposed a model to explain the magnetic behavior of layered compounds in relation to the basal spacing. This model assumes that the alkyl chains do not participate directly in the interlayer coupling but can noticeably affect the magnitude and the nature (ferromagnetic (FM) or antiferromagnetic (AFM)) of the in-plane coupling. In tum, the nature of the in-plane coupling determines the existence of long-range magnetic ordering. In case of ferromagnetic in-plane correlations, the magnetic property depends to a large extent on the interlayer spacing. For small spacings $(c<10 \AA)$, the interlayer interactions, dominated by superexchange through hydrogen bonds, stabilize a 3D AFM order between layers; a metamagnetic transition is observed at low fields, however. For large spacings, the compounds exhibit a spontaneous magnetization at zero fields below an ordering temperature. On the other hand, antiferromagnetic in-plane correlations result in an AFM 2D short-range order and no 3D order, as observed for copper(II) $n$-alkyl sulfates. ${ }^{\text {(ta) }}$

The present Cu-DS4 system shows a slightly anomalous magnetic behavior. In spite of antiferromagnetic in-plane correlations $(J<0)$, the magnetic properties of Cu-DS4 exhibit not an AFM 2D short-range order and no 3D order, but AFM 3D long-range order, which is the first case, to our knowledge. It should be noted that while the temperature dependence of dc magnetization indicated an antiferromagnetic (AFM) interaction, the history-dependence of $\mathrm{dc}$ magnetization $(\mathrm{ZFC} / \mathrm{FC}$ ), ac magnetization, and the field dependence of magnetization all suggest the existence of a ferromagnetic (FM) interaction in this system. In particular, the observed hysteresis behavior and the change in slope in the low field region of the $M-H$ curves revealed the exist- ence of noncollinear antiferromagnetic state due to the sulfonate-pillars within the copper hydroxide layer. These features are indicative of a metamagnet consisting of spincanted antiferromagnetic layers. The anomalous magnetic behaviors are understood by the existence of hydrogen bonding and disulfonate groups coordinated to magnetic layers, giving rise to slight in-plane structural modifications and thus to exchange interactions. In turn, owing to small basal spacings ( $c=10.836 \AA$ ), the interlayer interactions, dominated by superexchange through hydrogen bonds and coordination bonding, stabilize a 3D AFM order between layers, and a metamagnetic transition is observed at low fields.

\section{Conclusion}

A novel titled compound, $\mathrm{Cu}_{2}(\mathrm{OH})_{3}\left(\mathrm{O}_{3} \mathrm{SC}_{4} \mathrm{H}_{8} \mathrm{SO}_{3}\right)_{1 / 2}$, was prepared by anion exchange with copper hydroxy nitrate $\left(\mathrm{Cu}_{2}(\mathrm{OH})_{3} \mathrm{NO}_{3}\right)$ as the starting material. From the X-ray powder diffraction, the Cu-DS4 exhibits a pillared layered structure with organic layers tilted between the inorganic layers at a tilt angle $21.8^{\circ}$, which is the first disulfonatepillared copper hydroxide salt. TGA investigations show that Cu-DS4 has no lattice water and exhibits a high thermal stability up to $270^{\circ} \mathrm{C}$. According to FTIR study, disulfonate jons are completely exchanged and directly bonded to $\mathrm{Cu}$ (II) jons with complex binding mode and hydrogen bonding interaction. Magnetic measurements reveal that Cu-DS4 exhibits a metamagnet consisting of spin-canted antiferromagnetic layers with a Neel temperature of $11.8 \mathrm{~K}$ in spite of in-plane antiferromagnetic interactions.

Acknowledgment. This work was supported by the Korea Science and Engineering foundation (ROI -2005-000-10798-0 and Proton Accelerator User Program No. M102KS01000102K1901-01814) and by the Korea Research Foundation (Grant No. KRF-2004-005-C00060 and Brain Korea 21 Project in 2005). Measurements at the Seoul Center of the Korea Basic Science of Institute (KBSI) are gratefully acknowledged.

\section{References}

I. Alberti, G. In Coniprehensive Stpranolectlar Chenistry; Lehn, J. M., Eds.; Pergamon: Elmsford, New York, 1996; Vol. 7, p 151.

2. (a) Clearfield, A. Progr. Inorg. Chem, 1998, 47, 371. (b) Cao, G.; Hong, H.; Mallouck, T. Acc. Chem. Res, 1992, $25,420$.

3. Mitzi, D. M. Progr. Inorg. Cheni 1999, 48, I.

4. (a) de Jongh, L. J. Magnetic Properties of Layered Transition Metal Conplexes; Kluwer Academic Publishers: Dordrecht, 1990. (b) Laget, V.; Homick, C.; Rabu, P.; Drillon, M.; Ziessel, R. Coord. Chem, Rev. 1998, I78-180, 1533. (c) Fujila, W; Awaga, K.; Yokoyama, T. Appl, Clay Sci, 1999, 15, 281.

5. (a) Park, S.-H.; Kim, H. J. J. An. Cheni. Soc. 2004, 126, 14368. (b) Huh, Y.-D.; Kwon, S.-S. Bull. Korean Chen. Soc. 2005, 26, 2054. (c) Fan, W.; Sun, S.; Song, X.; Zhang. W.; Yu, H.; Tan, X.; Cao, G. J. Solid State Chem. 2004, 177,2329 . (d) Fan, W; Sun, S.; You, L.; Cao, G; Song, X.; Zhang, W; Yu, H. J. Mater: Chem. 2003, 13, 3062. (e) Liu, B.; Yu, S.-H.; Zhang, F.; Zhang L.; Li, 
Q.; Ren, L.; Jiang, K. J. Phys. Chem. B 2004, 108, 4338.

6. (a) Miyata, S.; Kumura, T. Chem. Lett. 1973, 843. (b) Yamanaka, S.; Sato, T.; Hattori, M. Chent. Lett. 1989, 1869. (c) Yamanaka, S.; Sato, T.; Seki, K.; Hattori, M. Solid State Ionics 1992, 53-56, 527. (d) Rabu, P;; Angelov, S.; Logoll, P.; Belaiche, M.; Drillon, M. Inorg. Chem. 1993, 32, 2463. (e) Rouba, S.; Rabu, P.; Ressouche, E.; Regnault, L.-P.; Drillon, M. J. Magn. Magn. Mater. 1996, 163 , 365.

7. (a) Rabu. P.; Rouba, S.; Laget, V.; Hornick, C.; Drillon. M. J. Chem. Soc., Chem, Comm, 1996, I107. (b) Laget, V.; Rouba, S.; Homick, C.; Drillon, M. J. Magn, Magn. Mater, 1996, 154, L7. (c) Rouba, S.; Rabu, P.; Ressouche, E.; Regnault, L.-P.; Drillon, M. J. Magn. Magn. Mater. 1996, J63, 365. (d) Laget, V.; Hornick, C.; Rabu, P.; Drillon, M.; Ziessel, R. Coord. Chem. Rev. 1998, I78-180, 1533.

8. (a) Fujila, W.; Awaga, K. Inorg. Chem. 1996, 35, 1915. (b) Fujita, W.; Awaga, K.; Yokoyama, T. Inorg. Chem, 1997, 36, 196. (c) Fujita, W.; Awaga, K. J. Am. Chem. Soc. 1997, 119, 4563. (d) Fujita, W.; Awaga, K.; Yokoyama, T. Appl. Clay Sci. 1999, 15, $28 \mathrm{I}$.

9. (a) Girtu, M.; Wynn, C. M.; Fujita, W.; Awaga, K.; Epstein, A. J. J. Appl. Phys. 1998, 83, 7378. (b) Girtu, M.; Wynn, C. M.; Fujila, W.; Awaga, K.; Epstein, A. J. Phys, Rev, 1998, B57, RI 1058. (c) Girtu, M.; Wynn, C. M.; Fujita, W.; Awaga, K.; Epstein, A. J. Phys. Rev, 2000, B61,4l17.

10. (a) Laget, V.; Hornick, C.; Rabu, P.; Drillon. M. J. Mater, Chen. 1999, 9, 169. (b) Laget, V.; Hornick, C.; Rabu, P.; Drillon, M.; Turek, P.; Ziessel, R. Ad, Mater. 1998, 10, 1024. (c) Laget, V.; Drillon, M.; Hornick, C.; Trabu, P.; Romero, F.; Turek, P.; Ziesssel, R.J. Alloys and Compounds 1997, 262-263,423.

II. Homick, C.; Rabu, P.; Drillon, M. Polyhedron 2000, 19, 259.
12. (a) Kurmoo, M. Chem, Mater, 1999, 11, 1546. (b) Kurmoo, M. Chent. Mater. 1999, 11, 3370. (c) Kurmoo, M. J. Mater. Chent. 1999, 9, 2595. (d) Huang, Z.-L.; Drillon, M.; Masciocchi, N.; Sironi, A.; Zhao, J.-T.; Rabu, P.; Panissod. P. Chem. Mater. 2000, 12, 2805. (e) Rabu, P.; Drillon, M.; Hornick, C. Analusis 2000, 28, 103. (I) Rabu, P; Drillon, M. Adr. Eng. Mater. 2003, 5, 189.

13. (a) Kurmoo, M.; Day, P.; Derory, A.; Estoures, C.; Poinsol, R. Stead, M. J.; Kepert, C. J. J. Sol. Stote Chem. 1999, 145, 452. (b) Taibi, M.; Ammar, S.; Jouini, N.; Fievet, F.; Molinie, P.; Drillon, M. J. Mater. Chem. 2002, 12,3238.

14. (a) Park, S.-H.; Lee, C. H.; Lee, C. E.; Ri, H.-C.; Shim, S. Y Mater, Res. Bull, 2002, 37, 1773. (b) Park, S.-H.; Lee, C. E. J. Phys. Chem. 2005, B109, 1118.

15. The molecular size $(\mathrm{O}-\mathrm{O})$ of 1,4 -butanedisulfonate anion is 8.44 $\AA$ using a semiempirical AM1 on HyperChem v5.02.

16. (a) Nakamolo, K. Infrared and Raman Spectra of Inorganic and Coordination Compounds, 5th ed.; John Wiley \& Sons: New York, 1997. (b) Colthup, N. B. Introduction to Infrared and Ranan Spectroscopy, 3rd ed.; Academic Press: 1990.

17. Effenberger, H. Z. Kristallogr. 1983, 165, 127.

18. Tarte, P. Spectrochin. Acta 1958, 13, 107.

19. Carlin, R. L. Magnetochemistry; Springer-Verlag: Berlin-Heidelberg, 1986.

20. Eltner, N.; Singh, R. R. P.; Young, A. P. Phys. Rev: Lett, 1993, 7l, 1629 .

21. (a) Takeda, T.; Bando, Y.; Kiyama, M.; Miyamoto, H. J. Phys. Soc. Jpn. 1966, 21, 2726. (b) Takeda, T.; Bando, Y.; Kiyama, M.; Miyamoto, H. J. Phys. Soc. Jpn. 1966, 21, 2745. (c) Miyamoto, H.; Shinjo, T.; Bando, Y.; Takeda, T. J. Phy:s. Soc. Jpn, 1967, 23, 1421 .

22. Drillon, M.; Panissod, P. J. Magn. Magn. Mater. 1998, 188, 93. 